\title{
USING BLOOM'S TAXONOMY AND GENDER DIFFERENCES TO ENHANCE THEORY AND PRACTICE IN GLOBAL EDUCATION
}

\author{
Hadjer Belhamidi ${ }^{1}$, Amina Mazouzi ${ }^{2}$ and Boulenouar Mohammed Yamin ${ }^{3}$ \\ ${ }^{1}$ African University of Adrar, Algeria \\ ${ }^{2}$ Saad Dahlab University of Blida, Algeria \\ ${ }^{3}$ Djilali Liabes University of Sidi Bel Abbes, Algeria
}

\begin{abstract}
Gender differences are important in theory vs. practice in education, and ignoring them causes the problem of incongruity instead of harmony with the material learnt. Psychiatrists have discovered a difference in the way the two genders handle theoretical and applied knowledge. This difference lies in genders' performance, whether they learn the theory alone, or practice what they learn. We will investigate how Bloom's Taxonomy (used by curriculum designers), particularly the psychomotor approach, would be misused by curriculum designers if they ignore the different patterns of reasoning and application of the two genders. Psychiatrists have discovered that females understand the theoretical knowledge better than the males, while the males on the other hand perform the application of the applied knowledge better than the females. As a result, countries/ schools/ syllabus designers that focus on theory more than they do on practice end up with a higher number of female students in schools, while the males tend to lose interest and drop out somehow. The same result occurs with majors that focus on theory alone, as literature, history, languages...etc. This research urges curriculum designers to consider gender differences in applying the psychomotor approach. The research analyzes how far curriculums consider application in order to help curriculum designers face problems at the level of gender differences. Researchers will find this study useful to understand how to use theory and practice to raise the level of students' performance in various majors
\end{abstract}

Keywords: Theory vs. Practice, Gender Psychological Differences, Bloom's Psychomotor Approach, Curriculum Designing, Education

\section{Introduction}

The educational approach, which is based on Bloom's Taxonomy (Classification, Categorization), is applied in any kind of learning and any field of study. Bloom, just like Ibn Khaldoun, explains how the acquisition process is systematic and can be categorized in an exact system or process to be followed and developed by teachers/ students or curriculum syllabus designers. The taxonomy is a set of techniques very useful for thinking and metacognition as well as paraknowledge, since it is composed of stages that instruct learners on how to know something, how to remember it, apply it and finally how to use it in other situations to create something new. In this sense, Bloom's Taxonomy is very purposeful in that it enables knowledge to be useful in real life situations, and prevents the pointless notion of the learning process (learning for the sake of a diploma versus learning for the sake of practicing the knowledge in real life).

\section{Practice as a Learning/ Teaching Process}

Based on the relationship between the material being learnt and the psyche of the learner, the psychomotor learning process is very useful in learning manual and verbal activities that involve repetition or practice such as pronouncing, articulating, writing, driving, sports...etc. The short story "18 Holes in His Mind" (Canfield and Hansen, 2008) illustrates the valuable use of theory-into-practice-notion, and the value of practice and repetition

Corresponding Author: Hadjer Belhamidi/ hanqiuzhouma @gmail.com 
in learning anything. Unfortunately, not all schools consider practice as a tool for knowledge; allowing students to only acquire and understand the theory, without practicing it. This happens in majors that focus on the theoretical knowledge alone (literature, history...etc.), in schools that lack practicing laboratories...etc. Ignoring practicing the knowledge prevents the students from grasping the knowledge, at the level of both the theory and the practical art, especially boys, since the experiments done in this research proved that girls grasp the theory better than boys, but when it comes to excellence in practice, boys perform better. One of the approaches of Bloom's Taxonomy is highly applicable in theory vs. practice, i.e.: practicing the theory or knowledge, and that is the psychomotor approach.

\section{The Psychomotor Learning/ Teaching Process}

The psychomotor learning process is one of the categories of Bloom's Taxonomy (Anderson and Sosniak, 1994), and it is divided into three stages, observing, imitating and practice.

Observing: It means to watch someone carry out the process you are trying to learn, or to hear someone say the things you are trying to learn. The more you watch or listen the more affective/ influential the information becomes, and the better you learn or the more influenced you become. The next stage is imitating.

Imitating: In this stage, you keep practicing with so much focus/ attention, i.e.: conscious imitation, until you have the ability to carry out the process on your own. Imitation involves repetition. For example, learning about the IPA or RP in a phonetics class merely involves the theoretic information, but students need to apply the theory frequently and repeatedly in order to pronounce better. This learning/ teaching process involves constant repetition, i.e.: only moving from the theoretic rules of pronunciation learnt in class into "manipulated theoretic repetition" into "unthinking/ automatic/robotic/ unaware/ unconscious/ repetition", would guarantee fluency in the best articulation possible. Repetition and practice are highly important and very effective and indeed necessary (obligatory) psychomotor activities to learn anything manual or verbal, especially pronunciation, so, in order for students to have a proper pronunciation, they must be provided with the native-speaker-in-classaudio materials to practice both listening and speaking. After that, you need practice, which is also another psychomotor activity.

Practice: Practice allows you to carry out the process with perfection, but more than that, practice stores the process you learn in your psychomotor skills, i.e.: a long-term memory so that (a) you would never forget the process, and (b) your process becomes automatic. This means that a student never needs to monitor the activity again, since the activity has become subconscious. On the other hand, this process makes males excel better than females, because their subconscious is more automatic. This automated process can be affected by gender differences (Wright and Payne, 1985). An automatic subconscious means that you no longer need to pay attention because the flow or current of the process does not fade or deviate or be distracted, which can be the case for females. In order to excel in a process, repeat it until it can be performed smoothly, with little or no attention at all. The process is at first conscious but the more you practice, the more it becomes unconscious or automatic, and demands no attention to be performed in a correct way, especially for men. It has been noticed however, in an arts class, that females may excel better than males in detailed crafts (The researchers conducted an experiment on males' and females' thinking and the results are approved when it comes to feminism and gender criticism: Females have a more meticulous or detailed thinking and performance while males are more general).

\section{The Defects of a Mere Theoretical Education Based on Gender Individual Differences}

The third world universities' teaching material can be inadequate concerning using/practicing the learnt material. If these countries provide a syllabus that establishes the first part of Bloom's Taxonomy of the cognitive approach, and fails to proceed to the next part of the practical knowledge, i.e.: if they provide the 
theoretical knowledge and neglect the practice, most students would fail, especially male students. This research explains the psychological sex differences (Elneel et al. 2008), which boys and girls differ in and which inflict their learning process. According to most theories, feminist, gender criticism as well as other psychological studies, males and females are different (Annett, 1983), but that does not mean they are unequal. We can say that males and females are equally different. This research has come up with the result that males' subconscious is stronger than the females', and as a result, they excel better in practical activities, such as driving...etc. Females' conscious abilities, on the other hand, are stronger and when it comes to the theoretical knowledge, they have no problem, but of course, when it comes to the practice, they show a lesser degree of performance than the males, except for exceptional cases. Bloom's Taxonomy asserts the necessity of the use of practice in order for students to master the learnt material. Education has to be based on both theory and practice. The research has discovered that there are more males than females in scientific majors where there are laboratories to practice the theoretical learnt material. On the other hand, in such majors where there is the theoretical knowledge alone, such as literature, civilization, linguistics majors where the researchers' universities provided the theoretical education alone, the research has discovered that there are more females than males enrolled. First analysis may reveal that it was a matter of preferences, i.e.: there are many male students in scientific majors because the males chose them because it is not boring for them if they practice the knowledge learnt. But the researchers of this study conducted a study on their own students, and they discovered that females are able to grasp the theory without practice, but they only show average results if they do not practice the learnt material. On the other hand, the researchers' study discovered that the male students find the theoretical knowledge boring and inadequate, and they must practice to achieve average or above average results. The research also discovered that, after a long-termed practice, male students can excel better than the females. The research steps were to conduct two exams; the exam of the first semester was theoretical alone. In the module of literary theory, students were given theoretical questions and definitions. The results were that females' performance was a little above average, with some exceptions below, while males' performance was average with a few exceptions below, knowing that the classes that the experiment was conducted on included students that share a very close level. In the second semester, after a long time of practice, the same students were given a practical exam in the same domain, and the result was that, female students' performance was $10 \%$ excellent, $50 \%$ above average and $20 \%$ below average. On the other hand, the male students' performance showed 30\% excellent and $60 \%$ above average. Thus, students of exact sciences cannot only study the theoretical knowledge of Mathematics, physics, chemistry...etc. without at least a certain amount of application or exercises. Students of chemistry, physics and biology will definitely fail to understand the rules if they are not provided with proper laboratories for experiments, and students of EFL will fail to achieve language proficiency without practicing the four skills in proper in-class-supervised practical work.

The researchers assumed that there might be another reason why there might be more male than female students in exact sciences majors (chemistry, math, physics, data processing...etc.), and more females than males in inexact knowledge majors. They assumed that males tend to choose those majors because (a) they like practicing and find theoretical education boring, (b) they find lab experiments more exciting and thrilling, (c) their subconscious is stronger and works better on experiments since many of them involve repetitive psychomotor processes, (c) they are more rational and logical than females and it would not enhance their level in fields which are romantic inexact irrational or illogical, such as literatures, arts...etc. However, these assumptions all fell down after the experiments conducted, apart from one, (c). Benjamin Bloom (Bloom and Krathwohl, 1956) asserted the necessity of practical education in his psychomotor approach, and the psychomotor scientists and psychiatrists have discovered that males' subconscious is stronger than females, and it enables them to (a) acquire knowledge better with practice, and (b) excel better than females after a longtermed practice (Fairweather, 2002). The males show a better performance of psychomotor activities, whereas the females' pattern of practice tends to break down with time because they tend to be less focused, more distracted, or more conscious, and thus, they break down the pattern of practice or unconsciously alter it since their subconscious is weaker, and the psychomotor activities depend on it. 
Students must have verbal/manual activities in classes/ laboratories, outside...etc. otherwise; the study of the theory alone would engage less learners belonging to one gender alone (females) and neglect the rest (males). Leading psychiatrists and gender critics have theorized the strength of male students' subconscious verbal/manual activities (as driving...etc.), and, on the other hand, the strength of female learners' mental activities (theory or thinking) (Donaldson and Kleinknecht, 1975). That does not mean that females are better writers, artists, sculptors or thinkers, but it means they can be average or above average writers, artists, sculptors and thinkers with the theoretical knowledge alone, because they perform better than boys when they both study the theoretical knowledge alone. On the other hand, males can be below average writers, artists, sculptors and thinkers after the theoretical knowledge alone. Thus, they must have the practical knowledge, but once they have it, they can master these skills better than girls.

Accordingly, males are rational, logical and think mostly using their conscious mind, while they use the subconscious mind in practice, while females are irrational, emotional, and illogical and they think using their subconscious mind. During a theoretical class relating to an inexact field (literature, poetry...etc.), the needed mental processes are illogical. Female students' thinking is already illogical; they do not need an excessive practice to understand the knowledge, and that gives them the edge. Therein, only the conscious activities of the students are needed (not psychomotor, verbal, practical, manual), in a field that demands exceptions instead of rules (illogical), and it helps the female learners' conscious because it is already illogical. That is the same as saying that females are more romantic or poetic than men with theory alone, but after practice, males become the excellent poets.

The male students would excel more if these illogical classes are provided with other classes of practical work, because in whichever field of science (logical, exact or illogical, inexact), practice is more exact and makes more sense than theory, especially to them. Provided that they have a practical work class in inexact fields (instead of spoon-feeding alone), male students will gain the edge over the females, because in practice, they use their subconscious.

Focusing on theory and neglecting practice that may occur in third world countries or developed countries when universities fail to provide laboratories and proper practicing outlets, or in inexact majors (literature, EFL, linguistics, history and civilization), involves female students in the syllabus and the neglects the male students. For majors that have laboratories to practice knowledge, such as chemistry...etc. more male students are involved in the course material, and it does not neglect the females either. However, majors or universities that do not focus on practice end up automatically (not deliberately) involving only females and neglecting male students, although female students need practice too. Thus, one of the aims of this study was to urge curriculum designers reconsider the practical part in education, because without it, the graduates will find their knowledge useless in real life.

\section{The Scope of the Research}

This research is done broadly to relate to the defects of education that may occur in places where the authorities may ignore the importance of practice or the psychomotor knowledge, and its impact on the two genders. The most important terms of this research are Bloom's Taxonomy (Krathwohl, 2002), the Freudian concepts (conscious vs. subconscious) and the logic vs. illogic. In Edgar Allan Poe's "The Purloined Letter" (Lacan and Mehlman, 1972), there are two different types of thinking: logical and illogical thinking. Accordingly, a logical person can never outsmart another illogical person, because a logical person is always be predictable, but an illogical person is always unpredictable, and that may make him a genius in some cases. In the short story, the logical Prefect tries to outsmart the illogical Mr. D, but fails to solve the case because he uses exact scientific logical thinking. He seeks the help of a man who is acquainted with both poetry (illogical) and mathematics (logical), and it is this illogical poet (Dupin) who outsmarts the villain and solves the case. Poe uses Dupin to 
explain how scientists, according to him, rely too much on exact rules and this prevents them from thinking outside the box, which the formal system of their education that is exact and can never change. It makes them too logical, always predictable, and in spite of making new inventions, their inventions are systematic and they follow rules, instead of uncertainties or exceptions as poets do, and that, according to him, makes poets smarter than mathematicians.

Poe then, toys with the notions of logic and illogic, stating that mathematicians only memorize and apply rules, while poets do not have rules, or the rules they have (values, virtues) are filled with illogical uncertainties, which makes them think more and memorize less. According to him, poets think more than mathematicians. Even though the story stereotypes the two notions of exact sciences (logic) against other fields of study (illogical), the researchers stands to believe that both fields of research, logical (math, physics, chemistry...exact sciences.) and illogical (literature, arts, history, politics...etc. inexact sciences) demand proper outlets for practice. This means that education, wherever it stands, in schools and universities, and in whichever fields or majors, needs to be both theoretical and practical.

Based on gender criticism, however, the story would take a wrong turn, since gender criticism defines men as being the rational beings and women the irrational more emotional beings. This is the notion that matters in this research: men are logical and women are more illogical, and driving on the Freudian notions of conscious and subconscious with Bloom's Taxonomy, we can recap that; the reason why females are numerous in theoretical majors and men are outnumbered is that with the theoretical education women can achieve above average levels, while men need practice to be excellent. Exceptional male students who practice at home can excel better than female students, though they are still outnumbered. The research came up with the following results:

Table 1 Gender Differences throughout Theoretical and Practical Education

\begin{tabular}{|l|l|l|l|l|l|}
\hline \multicolumn{3}{|c}{ Gender } & \multicolumn{3}{c|}{ Girls } \\
\cline { 2 - 6 } & Task $>$ & Processing data & Exam performance & Processing data & Exam performance \\
\cline { 2 - 6 } & Performance > & Below average & Below average & Average & Average \\
\cline { 2 - 6 } & Reason > & $\begin{array}{l}\text { Data is too } \\
\text { conscious to } \\
\text { remember }\end{array}$ & $\begin{array}{l}\text { Data forgotten } \\
\text { because not stored in } \\
\text { the subconscious }\end{array}$ & $\begin{array}{l}\text { Data consciously } \\
\text { understood and } \\
\text { remembered } \\
\text { temporarily }\end{array}$ & $\begin{array}{l}\text { Data memorized in } \\
\text { a short term } \\
\text { memory }\end{array}$ \\
\cline { 2 - 6 } & Performance $>$ & Excellent & Excellent & Processing data & Exam performance \\
\cline { 2 - 6 } & Reason $>$ & $\begin{array}{l}\text { Data stored in the } \\
\text { subconscious }\end{array}$ & $\begin{array}{l}\text { Unconscious data } \\
\text { easily managed }\end{array}$ & $\begin{array}{l}\text { Data stored in the } \\
\text { subconscious }\end{array}$ & $\begin{array}{l}\text { Unconscious data } \\
\text { hard to manage }\end{array}$ \\
\hline
\end{tabular}




\section{Analyses}

\section{Gender Critics \& the APA (Especially psychomotor researchers):}

1. Males and Females are equally different.

2. Males: rational, practical, logical, objective, reason using their mind...etc.

3. Females: irrational, theoretical, illogical, subjective, think using their emotions...etc.

\section{$>$ Theory-Based Education:}

1. Females grasp the theoretical part faster and more efficiently than the males.

2. The males need the practical part (with higher frequency) to grasp the theoretical part.

$>$ Practice-Based Education:

1. Majors of logical reasoning and practical exercises, such as exact sciences, which involve both theory and practice.

1. With more practice, male students have higher chances to achieve a higher success than female students do, especially in verbal, manual and all practical activities (psychomotor activities, such as sports, driving, military field manual activities...etc.)

\section{Deduction}

$>$ Males' psychomotor abilities are stronger than females because their subconscious is stronger (Bloom's Taxonomy of the psychomotor process illustrates that psychomotor activities become subconscious or automatic with repetition).

$>$ University majors with sufficient practical education, which involves practice/ application, have more male students than females because they provide labs...etc.

$>$ University majors with insufficient practical educational part (only theoretical) involve more female students than males because they do not provide an outlet for practice (language informal environment or labs...etc.).

$>$ Poor countries that fail to provide their students with an outlet for practice end up having most of their male students dropping out of schools, especially by high school.

\section{The Theoretical Education vs. the Practical Education}

Theoretical education is inadequate concerning practicing the learnt material. The theoretical knowledge is too conscious to be remembered for a long time. Our subconscious is bigger and deeper than our conscious and we must use it. With the theoretical knowledge, students' knowledge is conscious and stored in a short term memory. They need to practice it more with psychomotor activities (through the psychomotor approach) in order for the knowledge to survive longer in their subconscious. Through theoretical education alone, students quickly end up losing the acquired knowledge but if they practice it, it becomes stored in their subconscious mind and they remember it for a longer time.

Many countries of the third world provide a syllabus that establishes the first part of Bloom's Taxonomy (the cognitive approach/ theoretical), and fails to proceed to the practical part. Students of exact sciences cannot only study the theory of Mathematics without application or exercises. Students of chemistry, physics and biology will definitely fail to understand the rules of chemistry, physics and biology if they are not provided with proper 
laboratories for experiments, and students of EFL will fail to achieve language proficiency without practicing the four skills in proper in-class-supervised practical work sessions.

Example: In teaching a foreign language, in order to master listening and speaking, students must have practical sessions of listening (laboratories for listening supervised practical work).

In order to master reading and writing, students must be supplemented with the reading material in libraries (meaning inside libraries) in addition to practical reading sessions there, because the sessions of reading comprehension are merely theoretical, technical and formal, and they would not suffice.

The reason countries of the third world that focus mainly on learning the theory and neglect its practice, especially when it comes to majors of literature, history, art, linguistics, philosophy...etc., is because of their inability to provide labs or practicing outlets...etc. Bloom testifies that all sciences share the same exact systematic learning process that depends on both theory and practice (whether being exact or inexact science: literature, history, art, linguistics, philosophy, chemistry, math., sports, martial arts...etc.), without proper practice, the theory fails and is ultimately forgotten.

Information taught theoretically alone without practice is mostly stored in the conscious part of the memory and is easily forgotten, whereas information stored in the subconscious part after practice is memorized forever because it becomes unconscious information. Studies have shown that if the learnt data becomes unconscious it can even be part of our dreams. Students must have verbal/manual activities in classes/ laboratories, outside...etc. otherwise; the study of the theory alone would engage less learners (females alone). For both male and female learners, only with practice would the theory make sense because only after practice would the learner access to metacognition and paraknowledge.

\section{The Importance of Autonomous Education}

Students must be provided with supervised as well as unsupervised practical work sessions so that they learn the value of autonomous learning. It is far better to learn than to be taught, where the lure of the exotic and the bravery of discovery would disappear. Ibn Khaldoun said, "Learners who are educated by tyrant and controlling teachers become lazy, liars and malevolent. They are prone to becoming inhuman and dependent on others. Even worse, they are unwilling to acquire virtues and good morals. This, in fact, what happened to every nation who was in the grip of oppression" (Ibn Khaldoun, 1988).

When the educational system/ syllabus offers a poor practice outlet or none at all, students are supposed to find ways to practice on their own, since practicing demands a longer time than theory, and even in scientific majors when the education offers a practice outlet, students are still obliged to practice outside class. Not all nations who are lazy and dependent are oppressed, but they need to modify their syllabi (curricula) to fit the needs of all learners and both genders.

Males' psychomotor abilities are stronger than females because their subconscious is stronger (Bloom's Taxonomy of the psychomotor process illustrates that psychomotor activities become subconscious or automatic with repetition) with a few exceptions when females top the males in practice. University majors with sufficient practical educational part involve more male students than females because they provide labs...etc.

\section{Conclusion}

Bloom's Taxonomy is a very effective approach in all the learning process. The cognitive approach serves to process information from the stage of hearing it for the first time until the stage of being able to produce it and even modify it, and is thus obligatory to achieve learning proficiency. The affective approach on the other hand, 
appeals to students' emotions, motivates them to join the making of the lesson, and influences their lives outside classes. Finally, the psychomotor approach highlights their need for practice to master the learnt material.

In addition to that, Benjamin Bloom, the pioneering educational psychiatrist, has established these three categories to involve all the process of learning, based on (a) information alone, (b) information and learner's affection and (c) information and learner's psychology, to be able to help learners acquire information using three personal methods of approaching and processing information: cognition, affection and psychology.

Bloom's Taxonomy has defined itself a strong pillar in education in different levels of schools until university, in all fields of study and research. It has, thus, proved itself necessary on a multidisciplinary level (second language acquisition, philosophy, art, literature, history, science, physics...etc.), although taking it from the perspective of Edgar Allan Poe, it would seem to have less to do with students' intelligence when it comes to exact sciences.

Moreover, the taxonomy provides guidelines for future use of the learnt knowledge in post-graduation/ paraknowledge/ metacognition levels, and assures that information learnt is not only necessary for exams, rather it can be useful to create a self-employed student writer (of tourism guides...etc.), translator (of books...etc.), novelist...etc. Thus, its effectiveness lies in enabling students be creative and enabling them to use their knowledge in real life.

\section{References}

Bonnie M. Wright R. B. Payne, 1985, Effects of Aging on Sex Differences in Psychomotor Reminiscence and Tracking Proficiency. Journal of Gerontology, (2): 179-184.

Hugh Fairweather, 2002, Sex differences in cognition. Elsevier, Vol. 4, (3): 231-280.

Avolio, Bruce J. Waldman, David A, 1994, Variations in cognitive, perceptual, and psychomotor abilities across the working life span: Examining the effects of race, sex, experience, education, and occupational type. Psychology and Aging, Vol. 9 (3): 430-442.

Donaldson, David, Ronald, A. Kleinknecht, 1975, A Review of the Effects of Diazepam on Cognitive and Psychomotor Performance. The Journal of Nervous \& Mental Disease, (4): 123-140.

Elneel, F.H.F., Carter, F., Tang, B. et al., 2008, Extent of innate dexterity and ambidexterity across handedness and gender: Implications for training in laparoscopic surgery. Surgical Endoscopy, Vol. 22, (1): 31-37.

Annett M, Kilshaw D., 1983, Right- and Left-handed skills II: estimating the parameter of distribution of L-R differences in males and females. British Journal of Psychology, 74:269-283.

Lacan, Jacques and Jeffrey Mehlman, 1972, Seminar of "The Purloined Letter" in Yale French Studies. No. 48, French Freud: Structural Studies in Psychoanalysis, Yale University Press: 39-72.

Krathwohl, D. R., 2002, A Revision of Bloom's Taxonomy: An Overview. Theory into Practice, 41 (4), 212-

218.

Canfield, Jack and Mark Victor Hansen, 2008, Chicken Soup for the Soul: Tales of Golf and Sport (Maryland: Pneuma Books LLC).

Lorin W. Anderson, Lauren A. Sosniak, 1994, Bloom's Taxonomy: A Forty-year Retrospective (Indiana: NSSE). 
Bloom, Benjamin S. \& David R. Krathwohl, 1956, Taxonomy of Educational Objectives: The Classification of Educational Goals, by a Committee of College and University Examiners: Handbook 1: Cognitive domain. (New York: Longmans).

Hyman, S. Edgar, 1962, The Tangled Bank: Darwin, Marx, Frazer and Freud as Imaginative Writers (New York: Atheneum). 